\title{
Antalya-Finike yöresi portakal bahçelerinde kullanılan sulama sularının kalitelerinin belirlenmesi
}

\section{Determination of the qualities of irrigation waters used in Antalya-Finike orange orchards}

\section{Filiz ÖKTÜREN ASRİ, Elif Işıl DEMIRTAŞ, Nuri ARI}

Batı Akdeniz Tarımsal Araştırma Enstitüsü Müdürlüğü-Antalya

Sorumlu yazar (Corresponding author): F. Öktüren Asri, e-posta (e-mail): filizokturen@ hotmail.com

Yazar(lar)e-posta (Author e-mail): eemrahoglu@mynet.com, arinuri@mynet.com

\section{MAKALE BİLGİSİ}

Alınıs tarihi 17 Kasım 2017

Düzeltilme tarihi 10 Nisan 2018

Kabul tarihi 18 Nisan 2018

\section{Anahtar Kelimeler:}

Sulama suyu

Su kalitesi

Tuzluluk

SAO

Portakal

\begin{abstract}
$\ddot{O Z z}$
Türkiye portakal üretiminin \% 25'i Antalya ilinde gerçekleştirilmektedir. İlçeler arasında Finike portakal yetiştiriciliği açısından ayrı bir öneme sahiptir. Yetiştiriciliği etkileyen önemli faktörlerden biri olması nedeniyle, bu çalışmada portakal bahçelerinde kullanılan sulama sularının kalite özellikleri incelenmiştir. Bu amaçla bölgedeki 20 adet kuyu suyundan su örnekleri alınarak pH, EC, $\mathrm{Ca}^{+2}, \mathrm{Mg}^{+2}, \mathrm{Na}^{+}, \mathrm{K}^{+}, \mathrm{CO}_{3}^{-2}, \mathrm{HCO}_{3}^{-}, \mathrm{CI}, \mathrm{SO}_{4}^{-2}$ ve $\mathrm{B}$ analizleri yapılmıştır. Analiz sonuçlarına göre sodyum adsorpsiyon oranı (SAO), \% $\mathrm{Na}$ ve bakiye sodyum karbonat (BSK) değerleri hesaplanarak kalite sınıfları belirlenmiş̧ir. Araştırma sonuçlarına göre incelenen örneklerin \% 75'inin $\mathrm{C}_{2}(250-750 \mu \mathrm{mhos} / \mathrm{cm}$ aralığında yer alan 15 örnek) ve \% 20'sinin $\mathrm{C}_{3}(750-2250 \mu \mathrm{mhos} / \mathrm{cm}$ aralığında yer alan 4 örnek) tuzluluk sinıfina girdiği belirlenmiștir. Sulama suyu örneklerinin tamamı sodyum adsorbsiyon oranı (SAO) açısından 1.sınıf sulardır. Sonuç olarak incelenen sulama suyu örneklerinin portakal yetiştiriciliğinde verim ve kalite kayıplarına yol açmadan kullanılabileceği belirlenmiştir.
\end{abstract}

\section{ARTICLE INFO}

Received 17 November 2017

Received in revised form 10 April 2018

Accepted 18 April 2018

\section{Keywords:}

Irrigation water

Water quality

Salinity

SAR

Orange

\begin{abstract}
Antalya province produces about 25 percent of all oranges produced in Turkey. Finike is the most important district in terms of the cultivation of orange. The quality characteristics of the irrigation waters used in orange orchards were investigated in this study because it is one of the important factors affect to growing. For the purpose, water samples were taken from 20 wells in the region. Analyses of irrigation waters including $\mathrm{pH}, \mathrm{EC}, \mathrm{Ca}^{+2}, \mathrm{Mg}^{+2}, \mathrm{~K}^{+}, \mathrm{Na}^{+}$, $\mathrm{CO}_{3}^{-2}, \mathrm{HCO}_{3}^{-}, \mathrm{Cl}^{-}, \mathrm{SO}_{4}^{-2}$ and $\mathrm{B}$ were done. From the analyses results $\mathrm{SAR}, \mathrm{Na} \%$ and $\mathrm{RSC}$ values were calculated and quality classes were determined. The results showed that $75 \%$ (15

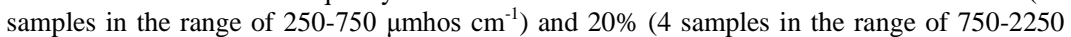
$\mu \mathrm{mhos} \mathrm{cm}^{-1}$ ) of the investigated water samples had moderate and high salinity, respectively. In term of SAR value, all samples were first class irrigation waters. As a result, it was determined that irrigation waters can be used in orange cultivation without yield and quality loss.
\end{abstract}

\section{Giriș}

Antalya ilinin Finike ilçesinin bitkisel üretim potansiyeli oldukça yüksektir. İlçenin 71010 dekar olan tarımsal arazi varlığında tarla bitkileri, meyvecilik (Turunçgiller, nar, bağ, zeytin vb.), örtüaltı ve açıkta sebze yetiştiricilik faaliyetleri sürdürülmektedir (Anonim 2018). İlçedeki meyvecilik faaliyetleri içerisinde Turunçgiller sahip oldukları tür ve çeşit zenginliği, meyvelerinin olgunlaşmasının uzun bir döneme yayılması ve olgunlaşan meyvelerin ağaç üzerinde bekletilebilmesi nedenleriyle ayrı bir öneme sahiptir. Türkiye'de Turunçgil yetiştiriciliği Güney Akdeniz ve kıyı Ege'nin güneyinde yaygın olup 88706 ha alanda yetiştiricilik yapılmakta olup, söz konusu üretim alanlarında 1779675 ton portakal, 725230 ton limon ve 229555 ton greyfurt üretilmiştir (FAO 2014). Antalya'da üretimi en yaygın olan turunçgil çeşidi portakaldır. 2017 yılı verilerine göre Antalya ili Finike ilçesi 29570 da alan ve 188264 ton portakal üretimi ile ilçeler arasında ilk sırada yer almaktadır (TUIK 2017). Bitkisel üretimde kullanılan kimyasal gübrelerin miktarı hızla artmaktadır. Antalya ili genelinde gübre kullanımı (34.4 $\left.\mathrm{kg} \mathrm{da}^{-1}\right)$ ülkemiz ortalamasının (28.75 $\mathrm{kg} \mathrm{da}^{-1}$ ) üstünde olup (Mencet Yelboğa ve Sayın 2013), özellikle Kumluca ve araştırma sahası olan Finike ilçelerinde oldukça yüksektir. Bitkisel üretim esnasında kullanılan gübrelerin toplam miktarının \% 5'inin yeraltı sularına karıştığı kabul edilirse (Mengel ve Kirkby 1987) 
tarımın aktif yapıldığı alanlarda yeraltı sularının takip edilmesinin önemi açığa çıkmaktadır. Yeraltı suları; deniz suyu, drenaj suları ve yağışların etkisi altında kaldığından ve kalitelerinin iyi olmamasının toprağın fiziksel yapısının bozulmasına, üretimde verim azalmasına yol açacağından dikkat edilmesi gereken önemli girdilerden biridir (Akay 1995). Ancak sulama sularının kalite düzeylerinin belirlenmesi bahçe tesisi sırasında dikkate alınmayan konulardan biridir. Oysaki tarımsal üretimin sürdürülebilirliğinin sağlanması, alınması gerekli drenaj tedbirlerinin belirlenebilmesi ve toprakta zamanla meydana gelebilecek fiziksel ve kimyasal değişikliklerin öngörülebilmesi açısından sulama suyunun kalitesinin belirlenmesi gerekmektedir (Ayers ve Westcot 1989). Nitekim Turunçgiller (portakal, limon, greyfurt) toprak ve sulama suyu tuzluluğuna karşı hassas bitkilerdir. Tuzluluk, yapraklardaki net karbondioksit asimilasyonunun, stoma iletkenliğinin, su potansiyelinin, büyümenin, klorofil miktarının, fotosentez oranının azalmasına, verim kayıplarına neden olduğu gibi (Levy ve Shalhevet 1990; Zekri 1991), yapraklarda sodyum ve klor gibi özel iyonların toksisitesine de yol açmaktadır (Levy ve Shalhevet 1990). Finike ilçesindeki tarımsal üretimin yapıldığı alanlarda kullanılan sulama sularının kalite kriterlerinin belirlendiği çalışmalar bulunmakla birlikte (Akay 1995; Tokmak 1995; Sönmez ve Kaplan 1996) bölge tarımının yoğun olması nedeniyle mevcut durumun ortaya konmasına ihtiyaç duyulmuştur. Bu nedenle çalışmada Antalya ili Finike ilçesinde yetiştiriciliği yaygın olan portakal'ın meyve verimi ve kalitesini etkileyen, toprak kalite parametreleri üzerine direkt etkili olan sulama sularının bileşiminin belirlenmesi amaçlanmıştır.

\section{Materyal ve Yöntem}

\subsection{Materyal}

Araştırma materyalini oluşturan sulama suyu örnekleri; Antalya ili Finike ilçesinde portakal yetiştiriciliği yapılan meyve bahçelerinden sulamaların yapıldığı Temmuz 2013 tarihinde, 20 tane kuyudan alınarak Batı Akdeniz Tarımsal Araştırma Enstitüsü Laboratuvarlarına gönderilmiştir. Sulama suyu örneklerinin alındığı yerler Şekil 1'de gösterilmiştir. Su örnekleri Ayyıldız (1990)'ın belirttiği şekilde, pompalar 15-20 dakika çalıştırıldıktan sonra temiz pet şişelere hava boşluğu kalmayacak şekilde alınmıştır. Işık almaması için kağıtla sarılarak aynı gün laboratuvara getirilmiştir.

\subsection{Yöntem}

Alınan sulama suyu örneklerinde $\mathrm{pH}$ ve EC Ayyıldız (1976)'ın bildirdiği şekilde; $\mathrm{Ca}^{+2}, \mathrm{Mg}^{+2}, \mathrm{~K}^{+}$ve $\mathrm{Na}^{+}$ konsantrasyonlar1 atomik absorpsiyon spektrofotometresi ile (Fresenius ve ark. 1988), $\mathrm{CO}_{3}^{-2}$ ve $\mathrm{HCO}_{3}^{-}$sülfürik asit titrasyonu, $\mathrm{Cl}^{-}$gümüş nitrat titrasyonu ile (Ayyıldız 1976), $\mathrm{SO}_{4}^{-2}$ baryum klorür ile ve B Azomethin-H yöntemiyle (Fresenius ve ark. 1988) belirlenmiştir. Yüzde sodyum oranının (Eşitlik 1), sodyum adsorbsiyon oranının (Eşitlik 2) ve bakiye sodyum karbonat'ın (BSK) (Eşitlik 3) belirlenmesinde (Ayyıldız 1976) tarafından önerilen eşitlikler kullanılmıştır. Sodyum adsorpsiyon oran1, bakiye sodyum karbonat ve elektriksel iletkenlik Soil Survey Staff (1954)'a göre; klor, sülfat, bor ve $\%$ Na ise Christiansen ve ark. (1977)'e göre değerlendirilmiştir.

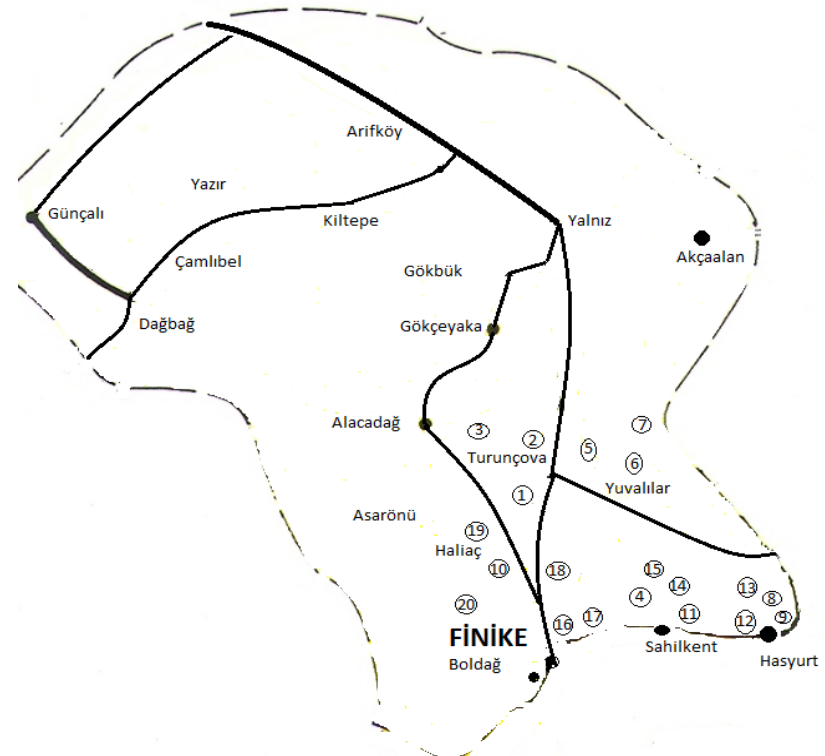

Şekil 1. Finike yöresinde su örneklerinin alındığı yerler.

Figure 1. Locations where water samples were taken in Finike.

$$
\begin{aligned}
& \% \mathrm{Na}=\left(\mathrm{Na}^{+} /\left(\mathrm{Na}^{+}+\mathrm{Ca}^{+2}+\mathrm{Mg}^{+2}+\mathrm{K}^{+}\right)\right) \times 100 \\
& \mathrm{SAO}=\mathrm{Na}^{+} /\left(\sqrt{\mathrm{Ca}^{+2}+\mathrm{Mg}^{+2}} / 2\right) \\
& \mathrm{BSK}=\left(\mathrm{CO}_{3}^{-}+\mathrm{HCO}_{3}^{-}\right)-\left(\mathrm{Ca}^{+2}+\mathrm{Mg}^{+2}\right)
\end{aligned}
$$

\section{Bulgular ve Tartışma}

Sulama sularının analiz sonuçları Çizelge 1'de verilmiştir. İncelenen sulama suyu örneklerinin pH'ları 6.8-7.9 arasında değişmektedir. Su örneklerinin \% 45'inin nötr $(6.6<\mathrm{pH}<7.3)$, $\% 45$ 'inin hafif alkali $(7.4<\mathrm{pH}<7.8)$ ve \% 10 'unun alkali $(7.9<\mathrm{pH}<8.4)$ karakterde olduğu tespit edilmiştir. Sulama suyu reaksiyonunun $(\mathrm{pH})$ 6.5-8.4 değerleri arasında olması istenir (Kanber ve ark. 1992). Çalışmada incelenen sulama suyu örneklerinin istenilen sınır değerlerini aşmadığı saptanmıştır.

Sulama amaciyla kullanılan suların kalitesi içerisinde çözünmüş olan tuzların toplam miktarına ve çeşidine bağlı olarak değişmektedir. Toplam iyon konsantrasyonunun artmasıyla birçok toprak ve yetiştiricilik sorunu geliştiğinden verim kayıplarının oluşmaması için önlemlerin alınması gerekir. İncelenen sulama suyu örneklerinin eriyebilir toplam tuz konsantrasyonlarının 97-1304 $\mu \mathrm{S} \mathrm{cm}^{-1}$ arasında değiştiği saptanmıştır. ABD Riverside Tuzluluk Laboratuvarı tarafından oluşturulan sınır değerlerine göre örneklerin \% 5'i 1 . sınıfta (düşük tuzlu), \% 75'i 2. sinıfta (orta tuzlu) ve \% 20'si 3. sinıfta (yükssek tuzlu) yer almıştır (Çizelge 2). Genel olarak bakıldığında örneklerin tamamına yakını 2. $\left(250-750 \mu \mathrm{S} \mathrm{cm}^{-1}\right)$ ve 3. sınıf $\left(750-2250 \mu \mathrm{S} \mathrm{cm}^{-1}\right)$ tuz içeriğine sahiptir. Bitkilerin tuza karşı dayanıklılıkları farklılık göstermektedir. Portakal tuza karşı hassas bitkiler arasındadır. 4 nolu $\left(1304 \mu \mathrm{S} \mathrm{cm}^{-1}\right) \mathrm{su}$ örneği portakalda \% 10 verim kaybına yol açabilecek düzeyde iken (Ayers ve Westcot 1989), diğer örneklerin toplam eriyebilir tuz konsantrasyonları portakal yetiştiriciliğinde verim kaybına yol açacak düzeyde değildir. 
Çizelge 1. Sulama suyu örneklerinin kimyasal analiz sonuçları.

Table 1. Chemical analysis results of irrigation water samples.

\begin{tabular}{|c|c|c|c|c|c|c|c|c|c|c|c|c|c|c|c|c|c|}
\hline \multirow{2}{*}{$\begin{array}{c}\text { Örnek } \\
\text { No }\end{array}$} & \multirow{2}{*}{$\mathrm{pH}$} & \multirow{2}{*}{$\begin{array}{c}\mathrm{EC} \\
\left(\mu \mathrm{S} \mathrm{cm}^{-1}\right)\end{array}$} & \multicolumn{4}{|c|}{ Katyonlar $\left(\mathrm{me} \mathrm{L}^{-1}\right)$} & \multicolumn{6}{|c|}{ Anyonlar $\left(\mathrm{me} \mathrm{L}^{-1}\right)$} & \multirow{2}{*}{$\frac{\mathrm{B}}{\left(\mathrm{mg} \mathrm{L}^{-1}\right)}$} & \multirow{2}{*}{$\mathrm{SAO}$} & \multirow{2}{*}{$\% \mathrm{Na}$} & \multirow{2}{*}{ BSK } & \multirow{2}{*}{$\begin{array}{l}\text { Kalite } \\
\text { Sinıfi }\end{array}$} \\
\hline & & & $\mathrm{K}$ & $\mathrm{Ca}$ & $\mathrm{Mg}$ & $\mathrm{Na}$ & $\sum \mathrm{K}$ & $\mathrm{CO}_{3}{ }^{-2}$ & $\mathrm{HCO}_{3}{ }^{-}$ & $\mathrm{Cl}^{-}$ & $\mathrm{SO}_{4}^{-2}$ & $\sum \mathrm{A}$ & & & & & \\
\hline 1 & 7.4 & 506 & 0.01 & 2.00 & 1.95 & 0.74 & 4.70 & - & 3.36 & 1.25 & 0.09 & 4.70 & 0.08 & 0.53 & 15.74 & -0.59 & $\mathrm{C} 2 \mathrm{~S} 1$ \\
\hline 2 & 6.9 & 97 & 0.01 & 0.55 & 0.10 & 0.05 & 0.71 & - & 0.47 & 0.22 & 0.02 & 7.10 & 0.06 & 0.09 & 7.04 & -0.18 & C1S1 \\
\hline 3 & 7.4 & 412 & 0.03 & 1.63 & 1.32 & 0.89 & 3.87 & - & 2.79 & 0.91 & 0.17 & 3.87 & 0.02 & 0.73 & 23.00 & -0.16 & $\mathrm{C} 2 \mathrm{~S} 1$ \\
\hline 4 & 7.9 & 1304 & 0.18 & 1.10 & 1.83 & 7.00 & 10.11 & - & 6.60 & 3.40 & 0.11 & 10.11 & 0.29 & 6.60 & 69.24 & 3.67 & $\mathrm{C} 3 \mathrm{~S} 1$ \\
\hline 5 & 7.2 & 606 & 0.04 & 4.10 & 3.28 & 0.56 & 7.98 & - & 5.14 & 0.65 & 2.19 & 7.98 & 0.02 & 0.29 & 7.02 & -2.24 & $\mathrm{C} 2 \mathrm{~S} 1$ \\
\hline 6 & 7.4 & 390 & 0.02 & 2.05 & 1.50 & 0.62 & 4.19 & - & 3.30 & 0.46 & 0.43 & 4.19 & 0.03 & 0.46 & 14.80 & -0.25 & $\mathrm{C} 2 \mathrm{~S} 1$ \\
\hline 7 & 7.1 & 801 & 0.05 & 5.72 & 4.57 & 0.76 & 11.10 & - & 6.83 & 0.8 & 3.47 & 11.10 & 0.02 & 0.34 & 6.85 & -3.46 & C3S1 \\
\hline 8 & 7.8 & 818 & 0.05 & 4.85 & 4.02 & 1.17 & 10.09 & - & 5.00 & 0.33 & 4.76 & 10.09 & 0.62 & 0.55 & 11.60 & -3.87 & C3S1 \\
\hline 9 & 7.5 & 742 & 0.14 & 2.75 & 3.08 & 4.95 & 10.92 & - & 6.00 & 1.66 & 3.26 & 10.92 & 0.77 & 2.91 & 45.33 & 0.17 & $\mathrm{C} 2 \mathrm{~S} 1$ \\
\hline 10 & 7.6 & 849 & 0.04 & 2.60 & 3.96 & 1.00 & 7.60 & - & 5.95 & 0.82 & 0.83 & 7.60 & 0.15 & 0.55 & 13.16 & -0.61 & C3S1 \\
\hline 11 & 7.9 & 323 & 0.03 & 1.30 & 1.55 & 1.04 & 3.92 & - & 2.39 & 1.32 & 0.21 & 3.92 & 0.02 & 0.87 & 26.53 & -0.46 & $\mathrm{C} 2 \mathrm{~S} 1$ \\
\hline 12 & 7.2 & 749 & 0.04 & 1.60 & 3.50 & 1.35 & 6.49 & - & 5.20 & 1.00 & 0.29 & 6.49 & 0.40 & 0.85 & 20.80 & 0.1 & $\mathrm{C} 2 \mathrm{~S} 1$ \\
\hline 13 & 7.2 & 732 & 0.06 & 3.07 & 4.17 & 0.91 & 8.21 & - & 7.24 & 0.95 & 0.02 & 8.21 & 0.02 & 0.48 & 11.08 & 0 & $\mathrm{C} 2 \mathrm{~S} 1$ \\
\hline 14 & 6.8 & 536 & 0.05 & 3.35 & 4.08 & 0.50 & 7.98 & - & 4.90 & 0.53 & 2.55 & 7.98 & 0.01 & 0.26 & 6.27 & -2.53 & $\mathrm{C} 2 \mathrm{~S} 1$ \\
\hline 15 & 7.8 & 396 & 0.06 & 3.65 & 3.42 & 3.30 & 10.43 & - & 4.45 & 1.45 & 4.53 & 10.43 & 0.19 & 1.76 & 31.64 & -.262 & $\mathrm{C} 2 \mathrm{~S} 1$ \\
\hline 16 & 7.3 & 620 & 0.03 & 2.95 & 3.00 & 0.53 & 6.51 & - & 4.65 & 0.60 & 1.26 & 6.51 & 0.08 & 0.31 & 8.14 & -1.3 & $\mathrm{C} 2 \mathrm{~S} 1$ \\
\hline 17 & 6.9 & 380 & 0.02 & 1.15 & 0.64 & 0.97 & 2.78 & - & 2.18 & 0.43 & 0.17 & 2.78 & 0.21 & 1.02 & 34.89 & 0.39 & $\mathrm{C} 2 \mathrm{~S} 1$ \\
\hline 18 & 7.3 & 520 & 0.01 & 1.70 & 1.41 & 1.33 & 4.45 & - & 2.87 & 1.23 & 0.35 & 4.45 & 0.16 & 1.06 & 29.89 & -0.24 & $\mathrm{C} 2 \mathrm{~S} 1$ \\
\hline 19 & 7.4 & 506 & 0.01 & 2.00 & 1.95 & 0.74 & 4.70 & - & 3.36 & 1.25 & 0.09 & 4.70 & 0.08 & 0.53 & 15.74 & -0.59 & $\mathrm{C} 2 \mathrm{~S} 1$ \\
\hline 20 & 7.4 & 412 & 0.03 & 1.63 & 1.32 & 0.89 & 3.87 & - & 2.79 & 0.91 & 0.17 & 3.87 & 0.02 & 0.73 & 23.00 & -0.16 & $\mathrm{C} 2 \mathrm{~S} 1$ \\
\hline
\end{tabular}

$\overline{\quad K}=$ Toplam Katyon, $\sum \mathrm{A}=$ Toplam Anyon, $\mathrm{SAO}=$ Sodyum Adsorpsiyon Oranı, \% Na= Yüzde Sodyum, BSK= Bakiye Sodyum Karbonat.

Çizelge 2. Su örneklerinin kalite sınıflarına göre değerlendirilmesi.

Table 2. Evaluation of water samples according to the quality classes.

\begin{tabular}{|c|c|c|c|c|c|}
\hline Parametreler & Sinıflar & Değerlendirme & Örnek Sayısı & $\%$ & Değerlendirme \\
\hline \multirow{4}{*}{$\mathrm{EC}\left(\mu \mathrm{S} \mathrm{cm}^{-1}\right)$} & $\mathrm{C} 1$ & $250>$ & 1 & 5 & \multirow{4}{*}{ Soil Survey Staff (1954) } \\
\hline & $\mathrm{C} 2$ & $250-750$ & 15 & 75 & \\
\hline & $\mathrm{C} 3$ & $750-2250$ & 4 & 20 & \\
\hline & $\mathrm{C} 4$ & $2250<$ & - & - & \\
\hline \multirow{6}{*}{ Klor (me L $\left.{ }^{-1}\right)$} & 1 & $0-3$ & 19 & 95 & \multirow{6}{*}{ Christiansen ve ark. (1977) } \\
\hline & 2 & $3-6$ & 1 & 5 & \\
\hline & 3 & $6-10$ & - & - & \\
\hline & 4 & $10-15$ & - & - & \\
\hline & 5 & $15-20$ & - & - & \\
\hline & 6 & $>20$ & - & - & \\
\hline \multirow{5}{*}{ Sülfat (me L ${ }^{-1}$ ) } & 1 & $0-3$ & 16 & 80 & \multirow{5}{*}{ Christiansen ve ark. (1977) } \\
\hline & 2 & $3-6$ & 4 & 20 & \\
\hline & 3 & $6-9$ & - & - & \\
\hline & 4 & $9-12$ & - & - & \\
\hline & 5 & $12-15$ & - & - & \\
\hline \multirow{6}{*}{ Bor $\left(\mathrm{mg} \mathrm{L}^{-1}\right)$} & 1 & $0-0.5$ & 18 & 90 & \multirow{6}{*}{ Christiansen ve ark. (1977) } \\
\hline & 2 & $0.5-1.0$ & 2 & 10 & \\
\hline & 3 & $1.0-2.0$ & - & - & \\
\hline & 4 & $2.0-3.0$ & - & - & \\
\hline & 5 & $3.0-4.0$ & - & - & \\
\hline & 6 & $4.0<$ & - & - & \\
\hline \multirow{4}{*}{ SAO } & 1 & $0-10$ & 20 & 100 & \multirow{4}{*}{ Soil Survey Staff (1954) } \\
\hline & 2 & $10-18$ & - & - & \\
\hline & 3 & $18-26$ & - & - & \\
\hline & 4 & $26<$ & - & - & \\
\hline \multirow{3}{*}{$\% \mathrm{Na}$} & 1 & $0-40$ & 18 & 90 & \multirow{3}{*}{ Christiansen ve ark. (1977) } \\
\hline & 2 & $40-60$ & 1 & 5 & \\
\hline & 3 & $60-70$ & 1 & 5 & \\
\hline \multirow{3}{*}{ BSK } & 1 & $>1.25$ & 19 & 95 & \multirow{3}{*}{ Soil Survey Staff (1954) } \\
\hline & 2 & $1.25-2.5$ & - & - & \\
\hline & 3 & $>2.5$ & 1 & 5 & \\
\hline
\end{tabular}

Sulama sularında bulunan en önemli katyonlar kalsiyum, magnezyum, sodyum ve potasyumdur (Zengin ve ark. 2008). İncelenen sulama suyu örneklerinin kalsiyum konsantrasyonları 0.55-5.72 $\mathrm{me} \mathrm{L}^{-1}$ arasında değişmekte olup Will ve Faust (1999) tarafından bildirilen yeterlilik sınır düzeyi 40-100 $\mathrm{mg} \mathrm{L}^{-1}$ (2-5 me $\mathrm{L}^{-1}$ ) ile karşılaştırılan örneklerin \% 40'1 düşük, \% 55'i yeterli ve \% 5'i yüksek düzeyde kalsiyum içermektedir. Sulama suyu örneklerinin magnezyum konsantrasyonları $0.1-4.57$ 
me $\mathrm{L}^{-1}$ arasında değişmektedir. Will ve Faust (1999) tarafından bildirilen 30-50 $\mathrm{mg} \mathrm{L}^{-1}\left(2.5-4.2 \mathrm{me} \mathrm{L}^{-1}\right)$ yeterlilik sınır değerine göre değerlendirilen örneklerin \% 50'si düşük, \% 45'i yeterli ve $\%$ 5'i yüksek düzeyde magnezyum içermektedir. Potasyum bitki büyümesi açısından önemli besin elementlerinden birisidir. Bitkiler için çok gerekli bir besin maddesi olan potasyum katyonunun sulama sularında olması genellikle istenir. Örneklerin potasyum konsantrasyonları 0.01-0.18 $\mathrm{me} \mathrm{L}^{-1}$ arasında değişmektedir. Sulama suları için $50 \mathrm{mg} \mathrm{L}^{-1}\left(2.2 \mathrm{me} \mathrm{L}^{-}\right.$ ${ }^{1}$ ) sodyum düzeyi uygun olarak bildirilmektedir (Will ve Faust 1999). İncelenen örneklerin sodyum konsantrasyonları 0.05-7.0 me $\mathrm{L}^{-1}$ arasında değişmekte olup örneklerin \% 85'inin sodyum içeriği normal sınırlardayken, \% 15'inin sodyum içeriği yüksektir. Sulama sularıyla toprakta biriken tuzların buharlaşma ve transpirasyonla konsantrasyonu arttıkça $\mathrm{Ca}$ ve $\mathrm{Mg}$ tuzlarının erirliliği azalır, ortamda çökelir ve sodyum toprak çözeltisinde erir halde kalır. Sodyum, kil minerallerindeki Ca ve $\mathrm{Mg}$ ile yer değiştirerek başat hale geçer. Böylece alkalilik başlar ve sodyum toprağın strüktürel yapısının ve geçirgenliğinin bozulmasına yol açar (İnce 1980). Sodyum içeriği en yüksek (7 me $\mathrm{L}^{-1}$ ) seviyede bulunan 4 numaralı örneğin kalsiyum ve magnezyum içerikleri düşüktür. Dolayısıyla sodyumun yaygın etkilerinin söz konusu sulama suyunun kullanıldığ görülmesi muhtemeldir.

Çalışma kapsamında incelenen sulama suyu örneklerinde karbonat bulunmamaktadır, bikarbonat $\left(\mathrm{HCO}_{3}^{-}\right)$içerikleri ise 0.47-7.24 me $\mathrm{L}^{-1}$ arasında değişmektedir (Çizelge 1). Örneklerin $\%$ 95'inin orta (1.5-8.5 me $\left.\mathrm{L}^{-1}\right)$ ve \% 5 'inin düşük $\left(<1.5 \mathrm{me} \mathrm{L}^{-1}\right)$ düzeyde bikarbonat içerdiği saptanmıştır. Sulama sularında bulunan karbonat ve bikarbonatlar kalsiyum ve magnezyum katyonları ile birlikte bulunması halinde önem kazanırlar. Su içinde bu iyonların konsantrasyonunun artması halinde kalsiyum ile birlikte çökelme eğilimleri artar. Magnezyum tuzları kalsiyum tuzlarına oranla daha çok eriyebildiklerinden daha az çökerler. Bu çökelme toprağın değişim materyalindeki ve çözelti fazındaki sodyum oranını yükselterek toprak alkaliliğini arttırmaktadır. Karbonat ve bikarbonat ile aynı konsantrasyonda $\mathrm{Ca}$ ve $\mathrm{Mg}$ içeren sulardaki bikarbonat iyonlarının alkalilik yönünden soruna neden olmayacağ genellikle kabul edilir. Ancak sulama suyunun $\mathrm{CO}_{3}{ }^{-2}$ ve $\mathrm{HCO}_{3}{ }^{-}$ konsantrasyonu iki değerli katyonlardan daha fazla ise, toprakta $\mathrm{Na}_{2} \mathrm{CO}_{3}$ birikimi meydana gelebilmektedir (Sağlam 1977). Bu açıdan değerlendirildiğinde 4, 9, 12 ve 17 nolu örneklerin $\mathrm{HCO}_{3}{ }^{-}$içeriklerinin toplam $\mathrm{Ca}+\mathrm{Mg}$ konsantrasyonlarından daha fazla olduğu belirlenmiştir. Konsantrasyonlar arasındaki fark 9, 12 ve 17 nolu örneklerde azdır. Ancak 9 (Na: 4.95 me L $\left.^{-1}\right)$ ve 4 (Na: $7.0 \mathrm{me} \mathrm{L}^{-1}$ ) nolu örneklerin sodyum konsantrasyonları da yüksektir. Dolayısıyla özellikle 4 numaralı sulama suyunun kullanılması aşamasında toprakta $\mathrm{Na}_{2} \mathrm{CO}_{3}$ birikimini önleyici tedbirlerin alınması gerektiği düşünülmektedir.

Bitki yetiştiriciliği açısından sorun yaratabilecek anyonlardan biri klordur. Turunçgiller klora karşı hassas bitkilerdir. Finike ilçesindeki portakal bahçelerinde kullanılan sulama sularının klor içerikleri 0.22-3.40 me $\mathrm{L}^{-1}$ arasında değişmektedir. Christiansen ve ark. (1977)'e göre değerlendirilen örneklerin $\% 95$ 'i 1 . sınıf ve $\% 5$ 'i ise 2 . sınıfa girmektedir. Tokmak (1995), Finike yöresinde tarımsal üretimde kullanılan sulama sularının klor içeriğinin 0.15-1.40 me $\mathrm{L}^{-1}$ arasında değiştiğini ve örneklerin tamamının klor içerikleri bakımından 1. sınıfa girdiklerini saptamıştır.

Sulama sularında kaliteyi etkileyen önemli faktörlerden biri de sülfattır. Yüksek sülfat içeriğine sahip olan sulama sularının kullanılması toprakta $\mathrm{CaSO}_{4}$ oluşmasına ve çökelmesine yol açar. $\mathrm{Bu}$ durumda toprak çözeltisindeki $\mathrm{Na}$ konsantrasyonu dolayısıyla SAO artar ve bu zararlı etki ise toprak özelliklerinin ve iyon bileşiminin bozulmasına neden olur (Modaihsh ve Alsadon 1994). İncelenen sulama suyu örneklerinin sülfat içerikleri 0.02-4.76 me L $\mathrm{L}^{-1}$ arasında değişmektedir. Christiansen ve ark. (1977)'e göre değerlendirilen örneklerin \% 80'i 1. sinıfta, \% 20'si ise 2. sinıfta yer almaktadır. Sönmez ve Kaplan (1996), Finike yöresinde örtüaltı domates yetiştiriciliği yapılan seralarda kullanılan sulama sularının özelliklerini belirledikleri çalışmalarında inceledikleri örneklerin tamamının sülfat içeriğinin 1. sınıfa dahil olduğunu belirlemişlerdir.

Bitki büyüme ve gelişmesi açısından mutlak gerekli mikro besin elementlerinden olan bor'a karşı turunçgiller hassas (0.5-0.75 $\mathrm{mg} \mathrm{L}^{-1}$ ) gruptadırlar. Söz konusu bitkilerin sulanmasinda kullanilacak suyun bor konsantrasyonu 0.3-1 $\mathrm{mg} \mathrm{L}^{-1}$ arasında olmalıdır. İncelenen sulama sularının bor içerikleri 0.01-0.77 $\mathrm{mg} \mathrm{L}^{-1}$ arasında değişmektedir. Christiansen ve ark. (1977)'e göre değerlendirilen örneklerin \% 90'1 1. sınıfa ve \% 10'u 2. sinıfa dahil olmuştur. İncelenen tüm sulama suyu örneklerinin bor düzeyleri turunçgillerde toksisite belirtisine yol açacak düzeyde değildir. Tokmak (1995), Finike yöresindeki tarımsal üretimde kullanılan sulama sularının kalite durumlarının belirlendiği çalışmada, incelenen örneklerin tamamının bor içeriklerinin 1. sınıfta yer aldığını bildirmiştir.

Sodyum Adsorpsiyon Oranı (SAO) değerleri 0.09-6.60 arasında değişen örneklerin tamamı az sodyumlu sınıfinda yer almıştır. Sulama suyunun sodyum adsorpsiyon oranının yüksek olması toprak çözeltisinin de SAO'nının artmasına yol açar. Bunun sonucunda toprağın değişebilir sodyum yüzdesi artar, toprak sodikleşme eğilimi gösterir (Varol ve ark. 2005). İncelenen sulama sularının sodyum adsorpsiyon oranları kullanıldıkları toprakların fiziksel özelliklerini olumsuz etkileyecek düzeyde değildir. \% Na değerleri 6.27-69.24 arasında değişen sulama suyu örnekleri Christiansen ve ark. (1977)'e göre değerlendirildiğinde örneklerin \%90'ının 1. sinıfa, \% 5'inin 2. sinıfa ve \% 5'inin 3. sınıfa dahil olduğu saptanmıştır. Öktüren Asri ve ark. (2010), Antalya ili Serik ilçesinde kullanılan sulama sularının kalite durumlarını belirledikleri çalışmalarında incelenen sulama sularının tamamının SAO ve \% Na değerlerinin 1. sınıfta yer aldığını bildirmişlerdir.

Bakiye sodyum karbonat (BSK) toprak özellikleri açısından oldukça önemlidir. $\mathrm{Na}_{2} \mathrm{CO}_{3}$ toprak içindeki organik maddeyi çözer, toprak kuru olduğu zaman yüzeyde siyah lekeler bırakır ve siyah alkali olarak bilinen toprakların oluşmasına yol açar. $\mathrm{Bu}$ topraklar kuru iken geniş çatlaklı, nemli iken yapışkan olduklarından işlemeye uygun değildirler (Ayers ve Westcot 1989). BSK değeri açısından, incelenen örneklerin \% 95'i 1. sınıfta $\left(<1.25 \mathrm{me} \mathrm{L}^{-1}\right)$ yer almıştır.

\section{Sonuç}

Meyve ağaçlarından uzun yıllar verim almak ana hedeftir. $\mathrm{Bu}$ nedenle bahçe tesis etmeden iklimin uygunluğu, toprak özellikleri, taban suyu ve drenaj sorunlarının tanımlanması, sulama suyunun varlığ 1 ve kalite düzeyi gibi yetiştiriciliği direkt etkileyen faktörlerin belirlenmesi gerekmektedir. Söz konusu faktörler arasında en gözardı edileni sulama suyunun kalite özelliklerinin tespitidir. Oysaki Turunçgil bitkileri sulama suyu içerisindeki özel iyonlara karşı hassastırlar. Antalya ili Finike ilçesinde portakal yetiştirilen bahçelerde kullanılan sulama sularının kalite düzeylerinin belirlendiği bu çalışmada, incelenen örneklerin \% 80'inin tuzluluk açısından sorun oluşturmadan, \%20'sinin ise drenaj sorununun olmadığ 
arazilerde kullanılabileceği saptanmıştır. \% $\mathrm{Na}$ ve sodyum absorbsiyon oranı (SAO) açısından değerlendirildiğinde sulama suyu örneklerinin kullanıldıkları topraklarda alkalilik tehlikesi meydana getirmeyeceği belirlenmiştir. Suların klor ve bor konsantrasyonlarının portakal bitkisinde iyon toksisitesine yol açacak düzeyde olmadığı tespit edilmiştir. Yöredeki üreticilerin tarımsal üretim esnasında yoğun bir şekilde gübre girdisini kullandığı, toprak ve su etkileşiminin devamlı olduğu gözönüne alındığında su kaynaklarında oluşabilecek kirliliğin izlenmesi, kirlenme açısından hassas bölgelerin belirlenmesi ve konu üzerinde ayrıntılı çalışmaların sürdürülmesi gerekmektedir.

\section{Kaynaklar}

Akay S (1995) Kumluca ve Finike Yörelerindeki Seraların Su ve Toprak Tuzluluğu Değişimlerinin Araştırılması. Yüksek Lisans Tezi, Akdeniz Üniversitesi Fen Bilimleri Enstitüsü, Antalya.

Anonim (2018) İlçemizde Tarım Sektörü http://www.finike.gov.tr/ilemizde-tarim-sektr. Erişim Tarihi 10 Nisan 2018.

Ayers RS, Westcot DW (1989) Water Quality for Agriculture, Irrigation and Drainage Paper 29, Rev.1. Food and Agriculture Organization of the United Nations, Rome.

Ayyıldız M (1976) Sulama Suyu, Sulama Suyu Kalitesi ve Sulamada Tuzluluk Problemleri. Ankara Üniversitesi Ziraat Fakültesi Yayınları No: 636, Ankara.

Ayyıldız M (1990) Sulama Suyu Kalitesi ve Tuzluluk Problemleri. Ankara Üniversitesi Ziraat Fakültesi Yayınları No: 1198, Ders Kitabı No: 334, Ankara.

Christiansen SE, Olsen EC, Willardson LS (1977) Irrigation Water Quality Evaluation. Journal of Irrigation and Drainage Div., ASCE, 103(IR 2): 155-169.

FAO (2014) Food and Agriculture Organization of the United Nations. www.fao.org/faostat/data

Fresenius W, Quentin KE, Schneidler W (1988) Water Analysis a Practical Guide to Physico-Chemical and Microbiological Water Examination and Quality Assurance. Springer-Verlag, New York.

İnce F (1980) Erzurum yöresinde bulunan bazı suların kalitelerinin saptanması üzerine bir araştırma. Atatürk Üniversitesi Ziraat Fakültesi Ziraat Dergisi 11: 127-134.

Kanber R, Kırda C, Tekinel O (1992) Sulama Suyu Niteliği ve Sulamada Tuzluluk Sorunları. Çukurova Üniversitesi Ziraat Fakültesi Yayınları No: 6, Adana.

Levy Y, Shalhevet J (1990) Ranking the Salt Tolerance of Citrus Rootstocks by Juice Analysis. Scientia Horticulturae 45: 89-98.

Mencet Yelboğa MN, Sayın C (2013) Antalya İlinde Serada Domates Üretiminde Gübre Kullanımının Yaşamsal Döngü Analizi. Selçuk Tarım ve Gıda Bilimleri Dergisi 27(1): 40-45.

Mengel K, Kirkby EA (1987) Principles of Plant Nutrition, 4th Edition. International Potash Institute Bern, Switzerland.

Modaihsh AS, Alsadon AA (1994) Response of two tomato varities to irrigation with sulphate waters. Journal of King Saud University Agricultural Science 6: 163-170.

Öktüren Asri F, Demirtaş EI, Arı N, Arpacıoğlu AE, Özkan CF (2010) Antalya-Serik Yöresi Seralarında Kullanılan Sulama Sularının Kalitelerinin Belirlenmesi. Akdeniz Üniversitesi Ziraat Fakültesi Dergisi 23(2): 145-150.

Sağlam MT (1977) Sulama sularında mevcut olan karbonat ve bikarbonat iyonlarının toprak üzerindeki zararlı etkilerinin belirlenmesinde kullanılan bazı kıstaslar. Atatürk Üniversitesi Ziraat Fakültesi Ziraat Dergisi 8: 129-137.

Soil Survey Staff (1954) Diagnosis and Improvement of Saline and Alkali Soils. Agriculture Handbook No: 60 US Departmant of Agriculture Washington DC.
Sönmez S, Kaplan M (1996) Kumluca ve Finike Yöreleri Sera Sulama Sularının Kalitelerinin Belirlenmesi. Akdeniz Üniversitesi Ziraat Fakültesi Dergisi 9: 288-303.

TUIKK (2017) Seçilmiş Göstergelerle Antalya 2017. www.tuik.gov.tr/ilGostergeleri/iller/ANTALYA.pdf.

Tokmak S (1995) Kumluca ve Finike Yörelerinde Tarımda Kullanılan Azotlu Gübrelerin Çevre Kirliliğine Etkileri. Yüksek Lisans Tezi, Akdeniz Üniversitesi Fen Bilimleri Enstitüsü, Antalya.

Varol F, Bellitürk K, Sağlam MT (2005) Tekirdağ İli Sulama Sularının Özellikleri. Tarım Bilimleri Dergisi 11: 391-396.

Will E, Faust EJ (1990) Irrigation Water Quality for Greenhouse Production. Agricultural Extension Service, The University of Tennessee, Tennessee.

Zekri M (1991) Effects of $\mathrm{NaCl}$ on Growth and Physiology of Sour Orange and Cleopatra Mandarin Seedlings. Scientia Horticulturae 47: 305-315.

Zengin M, Karakaplan S, Ersoy İ (2008) Determination of Irrigation Water Quality of Lake Beysehir and Other Water Sources Used in Irrigation of Çumra Plain. Asian Journal of Chemistry 20: 694-704. 